\title{
The association between paracetamol use and the risk of asthma, rhinitis and eczema in the Polish population
}

\author{
Agnieszka Lipiec ${ }^{1, A-F}$, Zbigniew M. Wawrzyniak ${ }^{1,2, C, F}$, Adam J. Sybilski ${ }^{13, B, E-F}$, \\ Urszula Samolińska-Zawisza ${ }^{1, A-B}$, Edyta Krzych-Fałta1,B,F, Barbara Piekarska',B,F, Grażyna Dulny'1,B,F, \\ Bożenna Stankiewicz-Choroszucha ${ }^{1, B, F}$, Filip Raciborski ${ }^{1, B, F}$, Bolesław Samoliński ${ }^{1, A-C, E-F}$ \\ ${ }^{1}$ Department of the Prevention of Environmental Hazards and Allergology, Medical University of Warsaw, Warsaw, Poland \\ ${ }^{2}$ Faculty of Electronics and Information Technology, Warsaw University of Technology, Warsaw, Poland \\ ${ }^{3}$ Department of Peadiatric and Neonatology, Central Clinical Hospital of the Ministry of Internal Affair, Warsaw, Poland \\ A - Research concept and design, B - Collection and/or assembly of data, C - Data analysis and interpretation, \\ $D$ - Writing the article, $E$ - Critical revision of the article, $F$ - Final approval of article
}

\begin{abstract}
Lipiec A, Wawrzyniak ZM, Sybilski AJ, Samolińska-Zawisza U, Krzych-Fałta E, Piekarska B, Dulny G, Stankiewicz-Choroszucha B, Raciborski $\mathrm{F}$, Samoliński B. The association between paracetamol use and the risk of asthma, rhinitis and eczema in the Polish population. Ann Agric Environ Med. 2018; 25(3): 428-432. doi: 10.26444/aaem/86336
\end{abstract}

\begin{abstract}
Introduction. A growing number of epidemiological studies suggest that paracetamol, which is commonly used in children, may be a risk factor for asthma, allergic rhinitis, and atopic eczema.

Objective. The aim of this study was to determine and characterize the correlation between paracetamol use and asthma, allergic rhinitis, and atopic eczema symptoms in the Polish population.

Materials and method. The study is part of the ECAP project involving the use of the ISAAC and ECRHS questionnaires. Completed questionnaires of 18,617 subjects, including 10,011 (53.8\%) females, were analyzed. Children aged 6-7 ( $n=4,510)$, adolescents aged $13-14(n=4,721)$, and adults aged $20-44(n=9,386)$ constituted $24.2 \%, 25.4 \%$, and $50.4 \%$ of respondents, respectively. Study subjects lived in 8 major urban centres and one rural area. The frequency of paracetamol use during the previous 12 months and symptoms of asthma, allergic rhinitis, and atopic eczema during that period were analyzed. Results. The use of paracetamol was associated with a significant dose-dependent increase in the risk of asthma symptoms in all evaluated age groups. This was demonstrated via odds ratios (OR) for developing asthma symptoms, including wheezing or whistling in the chest in 6-7-year-olds and exercise-induced shortness of breath in 13-14-year-olds and adults, depending on the frequency of paracetamol use in the previous 12 months, compared to no paracetamol intake during that period. Conclusions. The use of paracetamol in the last 12 months was associated with a significant dose-dependent increase in the risk of rhinitis and skin allergy symptoms, as demonstrated by the odds ratio. Therefore, frequent paracetamol use may be a risk factor for symptoms of asthma, rhinitis, and skin allergy in the Polish population.
\end{abstract}

\section{Key words}

asthma, rhinitis, eczema, paracetamol

\section{INTRODUCTION}

Abundant epidemiological observations from the last decades demonstrate a clear rise in the incidence of bronchial asthma and allergic rhinitis in developed countries [1]. Identifying the factors responsible for this phenomenon has been the objective of a number of research projects. One of the potential risk factors in the development of bronchial asthma is the use of paracetamol. Paracetamol is very commonly used, especially in children, as an analgesic and antipyretic, also as an ingredient of fixed-dose combinations [2]. In pain management strategies in children, whose pain is assessed as being mild, paracetamol is one of the medicines of choice [3]. An increasing number of publications indicate that paracetamol may be a risk factor for developing bronchial asthma. The published studies evaluated the effects of paracetamol exposure prenatally $[4,5,6,7]$, in early and

Address for correspondence: Agnieszka Lipiec, Department of the Prevention of Environmental Hazards and Allergology, Medical University of Warsaw, Poland, ul.Banacha 1a, 02-097 Warszawa, Poland

e-mail: alipiec@wum.edu.pl

Received: 11.01.2018; accepted: 07.03.2018; first published: 17.04.2018 late childhood $[8,9]$, adolescence $[10,11]$ and at adult age $[12,13,14]$. Paracetamol use may also be a risk factor for developing rhinitis, conjunctivitis, and eczema $[9,11]$. The suspected mechanisms behind the observed correlations involve oxidative stress in the airways with its effect on inflammation, as well as a strong Th2-mediated response $[15,16]$ or airway epithelial damage as the effect of inhibiting cyclooxygenase- 2 , which plays a role in the repair of damaged airway epithelium $[17,18]$.

\section{OBJECTIVE}

The aim of the study was to determine and describe any correlation between paracetamol use and developing symptoms of asthma, allergic rhinitis, and allergic skin lesions in children, adolescents, and adults participating in the Epidemiology of Allergic Diseases in Poland, ECAP programme. 


\section{MATERIALS AND METHOD}

Study population. The ECAP study used the complete European Community Respiratory Health Survey II (ECRHS II) and International Study of Asthma and Allergy in Childhood (ISAAC) questionnaires, translated into Polish and validated in a pilot study. Subjects living in the 8 largest Polish urban centres (each with a population of over 150,000) and one rural area (also with a population of over 150,000) were included in the study. The study group was randomized and stratified based on the PESEL number assigned to every Polish citizen. As in the ISAAC and ECRHS study protocols, this study included 3 groups of respondents; 6 - 7-year-old children, 13 - 14-year-old adolescents, and 20 - 44-yearold adults. A total of 22,703 respondents were included in the study; however 18,617 questionnaires (including 10,011 [53.8\%] questionnaires completed by females) met the ultimate quality assessment criteria. Children aged $6-7$ $(n=4,510)$, adolescents aged $13-14(n=4,721)$, and adults aged $20-44(n=9,386)$ constituted $24.2 \%, 25.4 \%$, and $50.4 \%$ respondents, respectively.

Questionnaire-based survey. The study was conducted via Computer Assisted Personal Interviewing (CAPI) with the use of Personal Digital Assistant (PDA). Completed questionnaires were automatically transferred to the central database with the use of General Packet Radio Service (GPRS) to form the database for analysis. The response "Yes" to the question on the use of paracetamol (including fixed combination drugs) during the last 12 months (v 462) required indicating the frequency of use, according to the following classification: 1) at least once a year or 2) at least once a month. Asthma symptoms were assessed via the following questions:

- Have you had wheezing or whistling in your chest at any time in the last 12 months? (v 136);

- Have you been woken up with a feeling of tightness in your chest in the last 12 months? (v 139);

- Have you had an attack of shortness of breath that came on during the day when you were at rest in the last 12 months? (v 140);

- Have you had an attack of shortness of breath that came on following strenuous activity in the last 12 months? (v 141).

Symptoms of rhinitis were identified with the following question: Have you ever had a problem with sneezing or a runny or blocked nose when you did not have a cold or flu in the last 12 months? (v 179).

Skin lesions were identified with the following questions: Have you ever had itchy skin changes coming and going for at least 6 months? (v 192);

- Have you had these itchy skin changes in the last 12 months? (v 193);

- Have these itchy skin changes at any time affected any of the following places: the folds of the elbows, behind the knees, in front of the ankles, under the buttocks or around the neck, ears or eyes? (v 194).

Statistical analysis. Differences between groups in terms of binary variables regarding symptoms and diagnoses were calculated with a chi-square test with the $\mathrm{P}$ value. Correlations between diagnoses and exposure / individual symptoms represented as binary variables were assessed via simple and multiple logistic regression analyses. Separate odds ratio (OR) values with their $95 \%$ confidence intervals (CI) were calculated for all potential risk factors, individual diagnoses, and age groups. Risk factors involved in the simple regression analysis were subsequently analyzed in a multiple logistic regression model. The analyses were performed with the IBM SPSS Statistics v.19.0 and Statistica v.10 (StatSoft, Inc., USA); some of the graphs were created with Excel v.2010, Microsoft.

The study was approved by the institutional Bioethics Committee sand carried out as part of the project "Implementation of the system for prevention and early diagnosis of allergic disorders in Poland" (No. 6 P05 2005 $\mathrm{C} / 06572$ ) funded by the Ministry for Health and Ministry for Science in Warsaw, Poland.

\section{RESULTS}

The proportion of respondents taking paracetamol at least once a month in the last 12 months was the highest at $41.29 \%$ $(n=3,866)$ in the adult (ages $20-44)$ group, with the relevant values in the youngest age group ( $6-7$ years) and in the group of 13 - 14-year-olds at $17.43 \%(n=782)$ and $26.33 \%(n=1,238)$, respectively. The mean rate of exposure to paracetamol at least once a month in the last 12 months in the total study population was $31.73 \%(n=5,886)$. The percentage of subjects who used paracetamol at least once during the last 12 months was highest in the youngest age group (6 - 7-year-olds) at $61.55 \%(n=2,761)$, with $51.76 \%(n=2,435)$ and $37,6 \%(n=3,520)$ in the groups of 13 - 14-year-olds and adults, respectively. A mean $46.99 \%(n=8,716)$ of the study population who completed this item of the questionnaire took paracetamol at least once during the previous 12 months.

Asthma. The reported intake of paracetamol in the last 12 months was associated with a significant dose-dependent increase in the risk of bronchial asthma symptoms in all evaluated age groups (Tab. 1).

The strongest correlation between the individual asthma symptoms and frequent paracetamol use of at least once a month was demonstrated in the youngest evaluated population of children 6-7 years of age. In this age group, the odds ratio (OR) values for wheezes/whistling in the chest with paracetamol use only once a year and at least once a month in the last 12 months, in comparison with no paracetamol use, were: 1.56 (95\% CI 1.26-1.93) and 2.82 (95\% CI 2.21-3.60), respectively. An equally strong risk-dose correlation was observed in the youngest age group for attacks of shortness of breath induced by strenuous activity, with OR=1.48 (95\% CI 1.13-1.94) for a single paracetamol use in the last 12 months and 2.82 (95\% CI 2.09-3.81) for frequent, once a month, use of the drug in the same period of time. A strong correlation between attacks of shortness of breath due to strenuous activity and frequent use of paracetamol was also observed in the group of adolescents (13-15 years old) and adults (20-44 years old), with $\mathrm{OR}=2.64$ (95\% CI 2.12-3.28) and $\mathrm{OR}=1.98$ (95\% CI 1.70-2.26), respectively.

Voluntary paracetamol use was not demonstrated to be greater in the group of respondents who reported symptoms of, and were diagnosed with, asthma than in the group who reported symptoms but without earlier asthma diagnosis, which could constitute a confounding factor (Tab. 2). 
Table 1. OR prevalence of 1) wheezing or whistling, 2) awakening with a feeling of tightness in the chest; 3) attacks of shortness of breath at rest; 4) attacks of shortness of breath after strenuous activity with respect to paracetamol usage

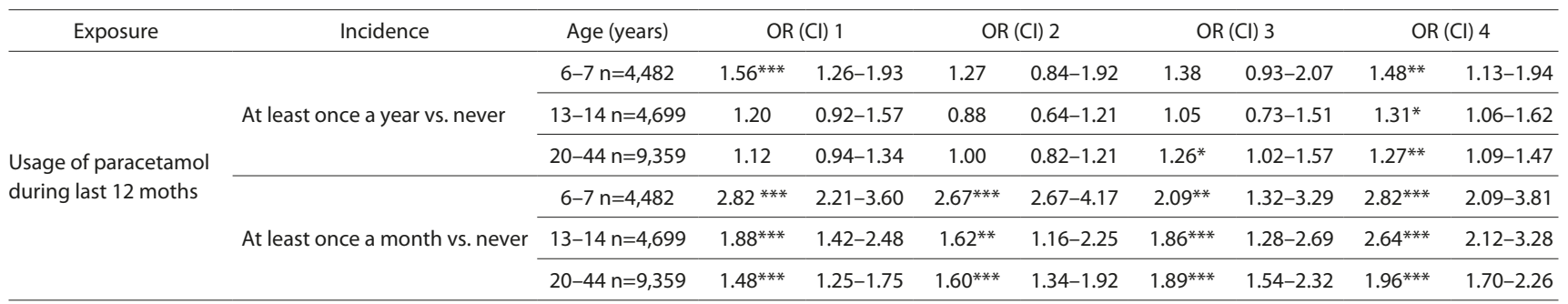

$\mathrm{p}^{*}<0.05 ; * *<0.01 ; * * * 0.001$

Table 2. Odds ratio of the use of paracetamol in the group of respondents who reported symptoms of wheezing or whistling, awakening with a feeling of tightness in chest, reported attacks of shortness of breath at rest, or attacks of shortness of breath after strenuous activity, while not being diagnosed with asthma vs. OR in the group of respondents who reported the above symptoms, as well as prior asthma diagnosis

\begin{tabular}{|c|c|c|c|c|}
\hline Exposure & Incidence & Age (years) & & (Cl) \\
\hline \multirow{6}{*}{$\begin{array}{l}\text { Usage of paracetamol } \\
\text { during last } 12 \text { moths }\end{array}$} & \multirow{3}{*}{$\begin{array}{l}\text { At least once a } \\
\text { year vs. Never }\end{array}$} & $6-7 n=1,160$ & $1.63^{*}$ & $1.02-2.58$ \\
\hline & & $13-14 n=1,212$ & 1.1200 & $0.72-1.73$ \\
\hline & & $20-44 n=2,933$ & 1.2400 & $0.87-1.76$ \\
\hline & \multirow{3}{*}{$\begin{array}{l}\text { At least once a } \\
\text { month vs. never }\end{array}$} & $6-7 n=1,160$ & 1.4400 & $0.85-2.44$ \\
\hline & & $13-14 n=1,212$ & 0.9000 & $0.58-1.40$ \\
\hline & & $20-44 n=2,933$ & 1.2600 & $0.90-1.76$ \\
\hline
\end{tabular}

$p^{*}<0.05$

Table 3. OR prevalence of 1) nasal allergy including hay fever 2) sneezing or a runny or blocked nose, without the common cold or flu, with respect to paracetamol usage

\begin{tabular}{|c|c|c|c|c|c|c|}
\hline \multirow[t]{2}{*}{ Exposure } & \multirow{2}{*}{$\begin{array}{l}\text { Incidence } \\
\text { At least }\end{array}$} & \multirow{2}{*}{$\begin{array}{l}\text { Age (years) } \\
6-7 n=4,470\end{array}$} & \multicolumn{2}{|c|}{$\mathrm{OR}(\mathrm{Cl}) 1$} & \multicolumn{2}{|c|}{ OR $(\mathrm{Cl}) 2$} \\
\hline & & & 0.97 & $0.82-1.16$ & 1.07 & $0.77-1.55$ \\
\hline \multirow{5}{*}{$\begin{array}{l}\text { usage of } \\
\text { para- } \\
\text { cetamol } \\
\text { during last } \\
12 \text { moths }\end{array}$} & once a & $13-14 n=4,695$ & 1.11 & $0.93-1.33$ & 1.29 & $0.95-1.74$ \\
\hline & never & $20-44 n=9,346$ & 1.03 & $0.90-1.33$ & 1.17 & $0.91-1.50$ \\
\hline & At least & $6-7 n=4,470$ & $1.45^{* *}$ & $1.16-1.79$ & 1.40 & $0.92-2.14$ \\
\hline & once a & $13-14 n=4,695$ & $1.58^{* * *}$ & $1.30-1.92$ & $1.75^{* *}$ & $1.25-2.47$ \\
\hline & vs. never & $20-44 n=9,346$ & $1.20 * *$ & $1.05-1.37$ & $1.35^{*}$ & $1.06-1.72$ \\
\hline
\end{tabular}

Rhinitis. The reported paracetamol use in the last 12 months was associated with a significant dose-dependent increase in risk of developing rhinitis symptoms (Tab. 3).

Nasal allergies. including hay fever, showed the strongest correlation, in terms of the odds ratio, with the use of paracetamol in the group of adolescents (13-14 years old) with frequent use of the drug (at least once a month); OR=1.58 (95\% CI 1.30-1.92)

Eczema. The use of paracetamol at least once a month in the last 12 months demonstrated a correlation (in terms of the odds ratio) with development of skin allergy symptoms (Tab. 4).

Frequent use of paracetamol in children 6-7 years old was associated with an increased risk of atopic eczema or other type of skin allergy and an itchy rash that was coming and going for at least 6 months, with itchy or watery eyes by $50 \%$ and $49 \%$, respectively (with $\mathrm{p}<0.05$ for either value). The rates of these forms of skin allergy in the adult population were higher by $44 \%$ and $45 \%$, respectively, than those in subjects who never used paracetamol $(\mathrm{p}<0.001)$.
Table 4. OR prevalence of: 1) eczema or any kind of skin allergy; 2) itchy rash coming and going for at least 6 months, with itchy or watery eyes, with respect to paracetamol usage

\begin{tabular}{|c|c|c|c|c|c|c|}
\hline Expo & cidence & Age (years) & \multicolumn{2}{|c|}{ OR $(\mathrm{Cl}) 1$} & \multicolumn{2}{|c|}{$\mathrm{OR}(\mathrm{Cl}) 2$} \\
\hline \multirow{6}{*}{$\begin{array}{l}\text { Usage of } \\
\text { para- } \\
\text { cetamol } \\
\text { during } \\
\text { last } 12 \\
\text { moths }\end{array}$} & \multirow{3}{*}{$\begin{array}{l}\text { At least } \\
\text { once a } \\
\text { year vs. } \\
\text { never }\end{array}$} & $6-7$ & 1.09 & 0.85 & 1.09 & 0.8 \\
\hline & & $13-$ & 0.9 & 0.7 & 0.9 & 0.7 \\
\hline & & 20 & 10 & 0.8 & 1. & 0.8 \\
\hline & \multirow{3}{*}{$\begin{array}{l}\text { At least } \\
\text { once a } \\
\text { month } \\
\text { vs. never }\end{array}$} & & $15 *$ & $1.11-2.01$ & 1. & 1. \\
\hline & & 1 & 0.9 & 0.7 & $1.34^{*}$ & 1.0 \\
\hline & & $20-44 n=9,346$ & $1.44 * * *$ & $1.16-1.79$ & $1.45^{* * *}$ & $1.16-1.80$ \\
\hline
\end{tabular}

$\mathrm{p}^{*}<0.05 ;{ }^{*}<0.01 ; * * *<0.001$

\section{DISCUSSION}

Epidemiology of Allergic Diseases in Poland (EACP) is a large questionnaire-based survey in the East-Central part of Europe, assessing the relationship between the usage of paracetamol and the symptoms of allergic diseases in children, adolescents, and adults. The data was collected from almost 20,000 subjects. The study was conducted in accordance with the standards of ISAAC and ECRHS, while addressing the Polish specificity. The accuracy of the surveys was high; with a multiple verification system introduced to ensure the accuracy of data obtained via modern teleinformation technologies.

The presented analysis of the frequency of paracetamol use in the ECAP study population suggests that this is a drug commonly used in the Polish population, with nearly half of the respondents (46.99\%) reporting its use at least once during the last 12 months, and almost one-third of all respondents (31.73\%) at least once a month during the last 12 months. A comparison of the findings on the use of paracetamol by the 13-14-year-olds with the results of the ISAAC Phase Three study [11], which analyzed a population of 322,959 adolescents from 113 study centers in 50 countries around the world, demonstrated the proportion of Poles who took paracetamol at least once during the last 12 months (51.76\%) to be slightly lower than the mean proportion for 50 countries assessed as part of ISAAC Phase Three (73\%). However, the proportion of Polish adolescents taking paracetamol at least once a month in the last 12 months (26.33\%) is comparable to the mean proportion from 50 countries participating in the ISAAC Phase Three study (30\%) [11].

The analysis of results from the ECAP study showed a correlation between the use of paracetamol in the last 12 months and a dose-dependent risk of developing symptoms of bronchial asthma, rhinitis, and skin allergy. This correlation was observed in all evaluated age groups, i.e. 
children 6-7-years-old, adolescents 13-14-years-old, and in young adults.

The correlation between wheezes/whistling in the chest or attacks of shortness of breath following strenuous activity in the last 12 months and frequent use of paracetamol measured with the odds ratio (OR) was 2.82 in the youngest evaluated age group (6 - 7-year-olds). This age group, analyzed by Beasley and the ISAAC Phase Three Study Group [11] based on a questionnaire-based survey in 205,487 children from 73 centres in 31 countries in the world, demonstrated a dose-dependent increase in the risk of developing asthma symptoms with paracetamol use at least once during the last 12 months (OR=1.61; 95\% CI 1.46-1.77) and with paracetamol use at least once a month during the last 12 months $(\mathrm{OR}=3.23$; 95\% CI 2.91-3.60). Moreover, the ISAAC Phase Three study showed that paracetamol use in children aged $6-7$ was associated with an increased risk of rhinitis and skin allergy symptoms; the currentr study showed comparable findings.

The correlation between the use of paracetamol and developing symptoms of asthma in the adolescent group (13 - 14-year-olds) assessed via a video questionnaire in the population of 322,959 adolescents in 113 centers representing 50 countries in the world, and published by Beasley and the ISAAC Phase Three Study Group [11], showed a 2.5fold increase in the risk of developing asthma symptoms during the last 12 months with the use of paracetamol at least once a month in the last 12 months; this result was comparable to that obtained in the current study. The ISAAC Phase Three Study also demonstrated a significant dosedependent correlation between paracetamol use and the risk of developing the symptoms of rhinitis and skin allergy in the group of 13 - 14-year-olds.

The ECAP study findings for the adult group are comparable to the results obtained by other authors. Shaheen et al. [12] were among the first to demonstrate a considerable increase in the risk of asthma symptoms with increased frequency of paracetamol use. With taking paracetamol less than once a month, the odds ratio (OR) was 1.06 (95\% CI 0.77-1.45), with dosing once a month $\mathrm{OR}=1.22(0.87-1.72)$, once a week $\mathrm{OR}=1.79$ (1.21-2.65), and with daily use of paracetamol $\mathrm{OR}=2.38$ (1.22-4.64) [12]. The correlation between the use of paracetamol and development of asthma in the adult population was assessed in the GA2LEN case-control study conducted in 12 European countries in order to compare a group of 521 patients reporting asthma and presenting its symptoms during the last 12 months, and a 507-person control group without either a diagnosis of asthma or its symptoms reported during the last 12 months. Weekly use of paracetamol proved to be strongly positively associated with asthma after controlling for confounders, in comparison with a less frequent use of the drug [13].

ECAP study results presented here are also consistent with the results of many other epidemiological studies conducted in various age groups and in various countries worldwide $[12,13,14,15,16,19,20,21]$. ECAP study results can be also compared to the results of the studies conducted in countries involved in the ISAAC Phase One study and ECRHS, which demonstrated that in countries with the highest per capita use of paracetamol, the prevalence of bronchial asthma is also high, which to some extent may indicates the existence of a correlation [22].

The final conclusions regarding any correlations between paracetamol use and developing the symptoms of asthma, rhinitis, and skin allergy, based on the ECAP study findings is limited by several confounding factors. Firstly, this study did not include any observations on the use of paracetamol in the earlier period, with only the 12 months directly preceding the study being analyzed. Conversely, such analysis of an earlier period was conducted, e.g. in the group of 6 - 7-yearolds included in the ISAAC Phase Three study mentioned above [9].

Moreover, the questions asked as part of the ECAP survey did not include the reasons for paracetamol use. However, it is worth noting that being more susceptible to respiratory tract infections, patients with asthma, especially children, are more likely to choose paracetamol for this reason than people without asthma. Moreover, viral respiratory tract infections, which in children are accompanied by fever which may be the reason for paracetamol use, may themselves constitute a risk factor for developing asthma [23]. Cheelo et al. [24], the authors of a recently published systematic review of cohort studies, conclude that respiratory tract infections confound the association between paracetamol exposure in early childhood and asthma. They found only weak evidence to support the association.

Another confounding factor that should be considered is the practice of avoiding the use of aspirin and other nonsteroidal anti-inflammatory drugs (NSAIDs) in those patients in whom aspirin may exacerbate the symptoms of asthma, and replacing those drugs with paracetamol, whenever indicated. This factor may be of greater importance in adults than in children. In order to eliminate this confounding factor, the presented study compared the selected symptomatic respondents without a diagnosis of asthma (i.e. the group where the voluntary replacement of other NSAIDs with paracetamol could not have played any role) with the group of patients reporting asthma diagnosis. The result does not indicate that this confounding factor plays a significant role in the study population.

One of the postulated mechanisms of asthma development involves oxidative stress in the airways, which affects bronchial inflammation and promotes bronchial hyper-responsiveness via injury of the respiratory epithelium [25]. Paracetamol is a potential source of oxidative stress, as its use results in a dose-dependent decrease in the levels of the endogenous pulmonary anti-oxidant glutathione (GSH) $[16,26,27$, 28]. Moreover, the Th2-mediated immunological response may become enhanced. Another postulated mechanism involves the role of paracetamol in selective inhibition of cyclooxygenase-2, which plays a role in repairing damaged airway epithelium $[17,18]$. Based on the study conducted in mice by Nassini et al. [29], a novel mechanism has been proposed. The researchers demonstrated that paracetamol intake caused metabolite NAPQI detectable concentrations in the lungs, which stimulated the transient receptor potential ankyrin-1 (TRPA1). That, in turn, led to neurogenic airway inflammation [29]. As frequent paracetamol use is also associated with symptoms of rhinitis and skin allergy, a systemic pro-inflammatory effect of paracetamol has also been postulated $[15,16,30]$. A study in a rat model, recently been published by Caballero et al. [31], demonstrated mast cells infiltration of nasal mucosa as a result of chronic exposure to paracetamol.

The ECAP study revealed a high incidence of both asthma and allergic rhinitis in the Polish population [32]. Frequent use of paracetamol may be one of risk factors for developing these 
conditions. However, researchers agree that well designed clinical trials and cohort studies are needed to determine such a correlation and dispel the doubts $[24,33,34]$.

Cheelo et al. [24], in the above cited meta-analysis, conclude that there is currently insufficient evidence to change the recommendations for paracetamol use. However, Allmers et al. [35] in a review presenting data published between 2000-2009, emphasize that the results justify warning the public that the excessive, uncritical use of paracetamol can result in asthma development [35]. It seems important in the era of increasing tendency to self-treatment with over-thecounter medicines, currently faced in Poland.

\section{CONCLUSIONS}

The correlations observed in the ECAP study indicate that frequent use of paracetamol may be a risk factor for developing symptoms of asthma, rhinitis, and skin allergy in the Polish population.

\section{REFERENCES}

1. Asher MI, Montefort S, Bjorksten B, et al. Worldwide time trends in the prevalence of symptoms of asthma, allergic rhinoconjunctivitis, and eczema in childhood: ISAAC Phases One and Three repeat multicountry cross-sectional surveys. The Lancet 2006; 368: 9537

2. Prescott LF. Paracetamol: past present and future. Am J Ther. 2000; 7(2): 143-7.

3. Mazur A, Radziewicz, Winnicki I, et al. Pain management in children. Ann Agric Environ Med. 2013; Special Issue: 28-34.

4. Shaheen SO, Newson RB, Henderson AJ, et al. Prenatal paracetamol exposure and risk of asthma and elevated immunoglobulin $\mathrm{E}$ in chldhood. Clin Exp Allergy 2005; 35: 18-25.

5. Rebordosa C, Kogevinas M, Sorensen HT, et al. Pre-natal exposure to paracetamol and risk of wheezing and asthma in children: a birth cohort study. Int J Epidemiol. 2008; 37(3): 583-90.

6. Persky V, Piotrkowski J, Hernandez E, et al. Prenatal exposure to acetaminophen and respiratory symptoms in the first year of life. Ann Allergy Asthma Immunol. 2008; 101(3): 271-278.

7. Perzanowski MS, Miller RL, Ali DB, et al. Prenatal acetaminophen exposure and risk of wheeze at age 5 years in an urban, low income cohort. Thorax 2010; 65: 118-123.

8. Del-Rio-Navarro BE, Ito-Tsuchiya FM, Berber A, et al. Study of the relationship beetween acetaminophen nad asthma in mexican children aged 6 to 7 years in 3 mexican cities using ISAAC metodology. J Investig Allergol Clin Immunol. 2008; 18(3): 194-202.

9. Beasley R, Clayton T, Crane J, et al. Association between paracetamol use in infancy and childhood, and risk of asthma, rhinoconjuncticitis, and eczema in children aged 6 - 7 years: analysis from Phase Three of the ISAAC programme. Lancet 2008; 372: 1039-48.

10. Kanabar D, Dale S, Rawat M. A review of ibuprofen and acetaminophen use in febrile children and the occurrence of asthma -related symptoms. Clin Ther. 2007; 29(12): 2716-23.

11. Beasley R, Clayton T, Crane J, et al. Acetaminophen use and risk of asthma, rhinoconjunctivitis and eczema in Adolescents ISAAC Phase Three. Am J Respir Crit Care Med. 2011; 183;171-178.

12. Shaheen SO, Sterne JA, Songhurst CE et al. Frequent paracetamol use and astma in adults. Thorax 2000; 16: 817-23.
13. Shaheen S, Potts J, Gnatiuc L, et al. The relation between paracetamol use and asthma: a GA2LEN European case-control study. Eur Resp J. 2008; 32(5): 1231-6.

14. Barr RG, Wentowski CC, Curhan GC, et al. Prospective study of Aceatminophen use and newly diagnosed asthma among women. Am J Respir Crit Care Med. 2004; 169: 836-841.

15. Eneli I, Sadri K, Camargo C, et al. Acetaminophen and the risk of asthma. The epidemiologic and pathophysiologic evidence. Chest 2005; $127 ; 604-612$.

16. Farquhar H, Stewart A, Mitchell E, et al. The role of paracetamol in the pathogenesis of asthma. Clin Exp Allergy 2010; 40: 32-41.

17. Hinz B, Cheremina O, Brune K. Acetaminophen (paracetamol) is a selective cyclooxygenase-2 inhibitor in man. FASEB J 2008; 22: 383-90.

18. Wallace JL. Commonality of defensive role of COX-2 in the lung and gut. Am J Pathol. 2006; 168: 1060-3.

19. Etminan M, Sadatsafavi M, Jafari S, et al. Acetaminophen use and the risk of asthma in children and adults: a systematic review and metaanalysis. Chest 2009; 136: 1316-1323.

20. Morales Suárez-Varela M, García-Marcos L, Fernández-Espinar JF. Is Acetaminophen Use Associated with Atopic Eczema and other Allergic Diseases in Adolescents? Iran J Allergy Asthma Immunol. 2013; 12: 115-123.

21. Gonzalez-Barcala FJ, Pertega S, Castro TP, et al. Exposure to paracetamol and asthma symptoms. Eur J Public Health. 2012; 23(4): $706-710$.

22. Newson RB, Shaheen SO, Chinn S, et al. Paracetamol sales and atopic disease in children and adults: an ecological analysis. Eur Respir J. 2000; 18: 817-823.

23. Tapiainen T, Dunder T, Mottonen M, et al. Adolescents with asthma or atopic eczema have more febrile days in early childhood: a possible explanation for the connection between paracetamol and asthma? J Allergy Clin Immunol. 2010; 125: 751-752.

24. Cheelo M, Lodge CJ, Dharmage SC. Paracetamol exposure in pregnancy and early childhood and development of childhood asthma: a systematic review and meta-analysis. Arch Dis Child. 2015; 100: 81-89.

25. Ochs-Balcom HM, Grant BJ, Muti P, et al. Antioxidants, oxidative stress, and pulmonary function in individuals diagnosed with asthma or COPD. Eur J Clin Nutr. 2006; 60(8): 991-9.

26. Dimova S, Hoet PH, Dinsdale D, et al Acethaminophen decreases intracellular glutathione levels and modulates cytokine production in human alveolar macrophages and type II pneumocytes in vitro. Int J Biochem Cell Biol. 2005; 37(8): 1727-37.

27. Kozer E, Evans S, Barr J, et al. Glutathione, glutathione dependent enzymes and antioxidant status in erythrocytes from children treated with high-dose paracetamol. Br J Clin Pharmacol. 2003; 55: 234-240.

28. Henderson AJ, Shaheen SO. Acetaminophen and asthma. Paediatric Resp Rev. 2013; 14: 9-16.

29. Nassini R, Materazzi S, Andre E, et al. Acetaminophen, via its reactive metabolite $\mathrm{N}$-acetyl-p-bezno-quinoneimine and transient receptor potential ankyrin-1 stimulation, causes neurogenic inflammation in the airways and other tissues in rodents. FASEB J. 2010; 24: 4904-16.

30. Nuttall SL, Khan JN, Thorpe GH et al. The impact of therapeutic doses of paracetamol on serum total antioxidant capacity. J Clin Pharm Ther. 2003; 28(4): 289-94.

31. Caballero N, Welch KC, Carpenter PS, et al. Association between chronic acetaminophen exposure and allergic rhinitis in a rat model. Allergy Rhinol. 2015; 6:162-167.

32. Samoliński B, Sybilski AJ, Raciborski F, et al. Prevalence of rhinitis in Polish population according to the ECAP (Epidemiology of Allergic Disorders in Poland) study. Otolaryngol Pol. 2009; 63(4): 324-30.

33. Holgate ST. The Acetaminophen Enigma in Asthma. Am J Respir Crit Care Med. 2011; 183: 147-151.

34. Shaheen SO. Acetaminophen and childhood asthma: Pill-popping at our peril? J Allergy Clin Immunol. 2015; 135: 449-50.

35. Allmers H, Skudlik Ch, Malte J S. Acetaminophen Use: A Risk for Asthma? Curr Allergy Asthma Rep. 2009; 9: 164-167. 